\title{
Soil hydraulic functions of international soils measured with the Extended Evaporation Method (EEM) and the HYPROP device
}

\author{
Uwe Schindler ${ }^{1^{*}}$ and Lothar Müller ${ }^{1}$ \\ ${ }^{1}$ Leibniz Centre for Agricultural Landscape Research (ZALF), Müncheberg, Institute of Landscape \\ Hydrology, Eberswalder Str. 84, D-15374 Müncheberg, Germany \\ *email: schindler.rehfelde@gmail.com
}

\begin{abstract}
The paper presents a database of 173 soil hydrological data (raw data) from 71 sites all over the world (Asia, Africa, Australia America and Europe). The undisturbed samples were mainly collected and measured as part of research projects. The soils cover a wide range of texture classes and dry bulk densities. The database consists of water retention and unsaturated hydraulic conductivity data. Additional data like the particle size distribution, the dry bulk density, the organic matter content and other variables are included. Until 2007 the common evaporation method was applied. Since 2008 the hydraulic data were measured with the Extended Evaporation Method (EEM) and the HYPROP device in the range between saturation and close to the permanent wilting point, defined at pF 4.2. Information to the geo reference, the soil type, the sampling depth and the horizon are given. Data access: http://dx.doi.org/10.4228/ZALF.2003.273.
\end{abstract}

Keywords: soil hydraulic data, water retention curve, unsaturated hydraulic conductivity function, Extended Evaporation Method (EEM), HYPROP.

1 INTRODUCTION: Knowledge of hydraulic functions is a precondition for predicting water and solute movement in soils. During the last decades, numerous measurement procedures have been developed. Currently. a broad array of methods exist to determine soil hydraulic properties either in the field or in the laboratory (Klute and Dirksen, 1986, Dane and Topp, 2002, Schindler et al., 2010). However, the effort and the cost for measuring hydraulic properties are very high. Therefore soil hydraulic databases were created to capitalize the measured soil hydraulic 25 properties, and and pedotransfer functions were developed. The UNSODA, UNsaturated hydraulic SOil DAtabase was developed in the mid of the eighties in the US Salinity Laboratory (Nemes et al., 2001). This database consists of hydraulic data from all over the world. The European databases HYPRES, HYdraulic PRoperties of European Soils, was created at the beginning of the 90th within a European project (Wösten et al., 1999). The extension of the European database EU-HYDI, EUropeanHYdropedological Inventory, was finished in 2013 (Toth, 2013). These data are often required by many researchers who do not have the possibility to make the measurements themselves. However, not all measured data are collected in these databases and to get access to the data of the European databases is limited.

In the period between 2000 and 2012 soil hydrological functions- water retention curve and unsaturated hydraulic conductivity function- of 173 soil samples with different textures, organic matter contents and origins were measured in several countries all over the world. These data are not part of the existing data basis (UNSODA, HYPRES, EU-HYDI) and are published in this paper.

\section{MATERIALS AND METHODS}

2.1 SOILS AND SITES: The 173 samples were collected from different locations all over the world in the countries: Australia, Brazil, Canada, Chile, China, Kazakhstan, New Zealand, European part of Russia and Siberia, Spain, Tanzania, USA (Table 1, Fig. 1). Most sites were experimental fields of research institutes and universities. The undisturbed samples in stainless steel cylinders of $8 \mathrm{~cm}$ in diameter and $5 \mathrm{~cm}$ in height were mainly collected and characterised as part of research projects. 
Figure 1. Location of the sampling points

Figure 2. Distribution of texture classes according to FAO (1990).

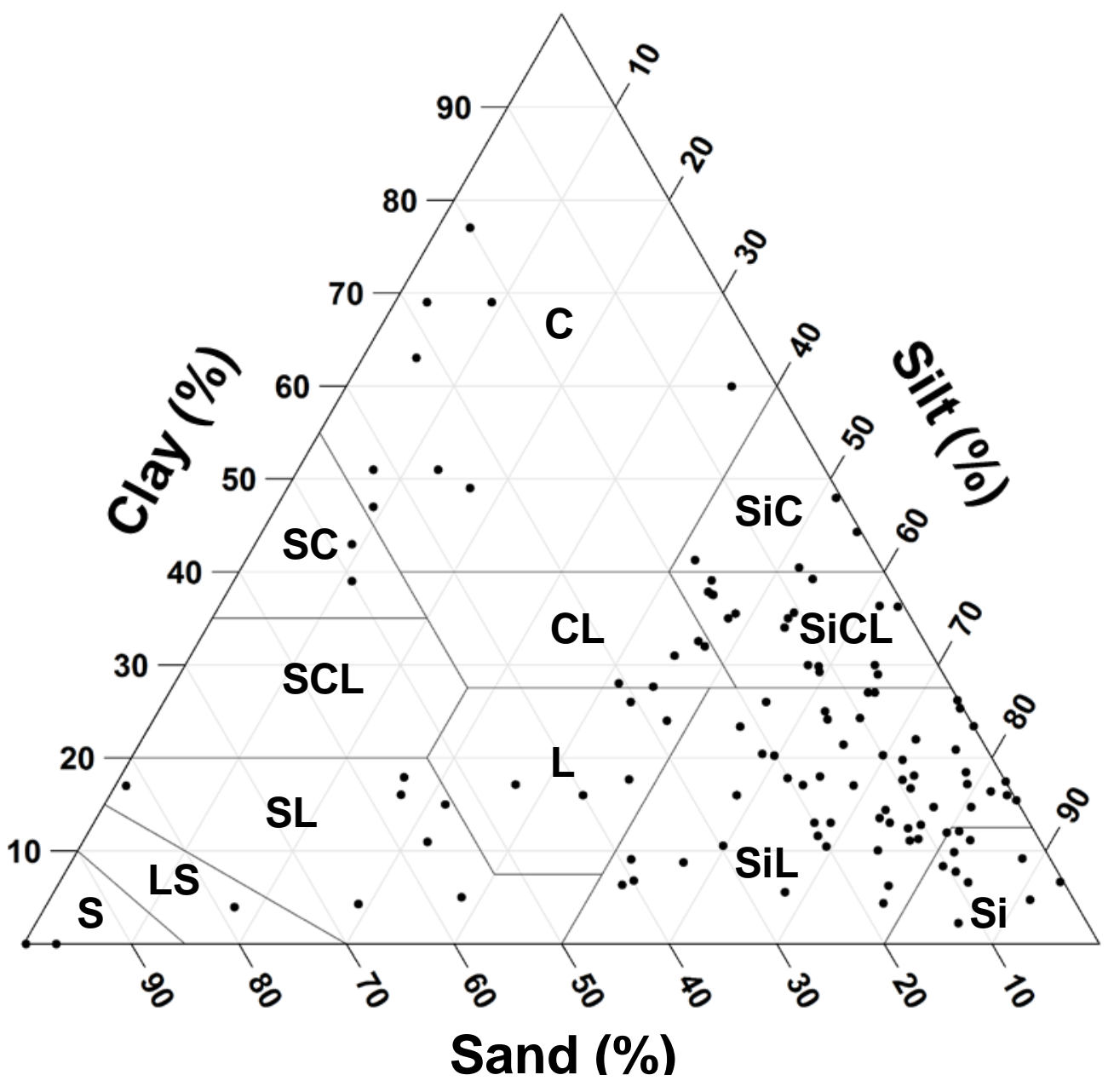




\begin{tabular}{lc}
\hline Table 1. Country and number of samples \\
\hline Country & Number of samples \\
\hline Australia & 2 \\
Brazil & 6 \\
Canada & 9 \\
Chile & 14 \\
\hline China & 29 \\
Kazakhstan & 13 \\
New Zealand & 4 \\
Russia & 44 \\
\hline Spain & 5 \\
Tanzania ${ }^{1)}$ & 18 \\
USA & 29
\end{tabular}

1) The samples were collected by Dr. B. Böhme (University Freiberg, Germany) and Prof. Method Kilasara, Sokoine University in Tanzania. The measurements of soil hydraulic functions were released in the Institute of Hydrology of the ZALF Müncheberg Germany.

2.2 STRUCTURE AND CONTENT OF DATABASE: The database includes soil hydrological data (raw data) and additional information to the geo reference, the soil type and the horizon, the particle size distribution, the dry bulk density and other parameters and is available at the homepage of the ZALF. Methodical information to the methods and the measurements techniques are given in the following. The structure of the database is according to Table 2.

Table 2. Database content and structure

\begin{tabular}{|c|c|c|}
\hline \multirow{2}{*}{$\begin{array}{l}\text { Work sheet } \\
\text { Basic data }\end{array}$} & \multicolumn{2}{|c|}{ Information and data } \\
\hline & \multicolumn{2}{|c|}{ Sample ID- Geo reference (ETRS89) } \\
\hline & \multicolumn{2}{|c|}{ Site } \\
\hline & \multicolumn{2}{|l|}{ Country } \\
\hline & \multicolumn{2}{|l|}{ Sample No. } \\
\hline & \multicolumn{2}{|l|}{ Sampling date } \\
\hline & \multicolumn{2}{|c|}{ Land use } \\
\hline & \multicolumn{2}{|c|}{ RSG (Reference soil group, WRB, 2006) } \\
\hline & \multicolumn{2}{|c|}{ Horizon } \\
\hline & \multicolumn{2}{|c|}{ Sampling depth } \\
\hline & \multicolumn{2}{|c|}{ Dry bulk density $\mathrm{cm}^{3} \mathrm{~cm}^{-3}$ ) } \\
\hline & \multicolumn{2}{|c|}{ Organic matter content (\%) } \\
\hline \multirow[t]{12}{*}{ Particle size distribution (PSD) } & \multicolumn{2}{|c|}{ Sample ID- Geo reference (WGS84) } \\
\hline & \multicolumn{2}{|c|}{ Site } \\
\hline & \multicolumn{2}{|c|}{ Country } \\
\hline & \multirow{2}{*}{\multicolumn{2}{|c|}{ Sample No. }} \\
\hline & & \\
\hline & \multicolumn{2}{|c|}{ Clay: $\quad<2 \mu \mathrm{m}$} \\
\hline & Fine silt: & $2-6.3 \mu \mathrm{m}$ \\
\hline & Medium silt: & $6.3-20 \mu \mathrm{m}$ \\
\hline & Coarse silt: & $20-63 \mu \mathrm{m}$ \\
\hline & Fine sand: & $63-200 \mu \mathrm{m}$ \\
\hline & Medium sand: & $200-630 \mu \mathrm{m}$ \\
\hline & Coarse sand: & $630-2000 \mu \mathrm{m}$ \\
\hline \multirow[t]{5}{*}{ Soil water retention function } & \multicolumn{2}{|c|}{ Sample ID- Geo reference (ETRS89) } \\
\hline & \multicolumn{2}{|c|}{ Site } \\
\hline & \multicolumn{2}{|l|}{ Country } \\
\hline & \multicolumn{2}{|c|}{ Sample No. } \\
\hline & \multicolumn{2}{|c|}{ Value pairs: tension $(\mathrm{hPa})$ and water content (\% by vol } \\
\hline $\begin{array}{l}\text { Unsaturated hydraulic } \\
\text { conductivity }\end{array}$ & \multicolumn{2}{|c|}{$\begin{array}{l}\text { Sample ID- Geo reference (ETRS89) } \\
\text { Site }\end{array}$} \\
\hline
\end{tabular}


Country

Sample No.

Value pairs: tension (hPa) and hydraulic conductivity $\left(\mathrm{cm} \mathrm{d}^{-1}\right)$

2.3 MEASUREMENT OF SOIL HYDRAULIC PROPERTIES: The measurements of soil hydraulic functions by means of the evaporation method were realised in the Institute of Hydrology of the ZALF Müncheberg Germany.

In the period from 2000 to 2007 the evaporation method according to Schindler (1980) was applied. This method allows the simultaneous determination of the water retention curve and the unsaturated hydraulic conductivity in the range between water saturation and about $500 \mathrm{hPa}$.

Since 2008 the Extended Evaporation Method (EEM, Schindler et al., 2010) using the HYPROP device (HYdraulic PROPerty analyzer, UMS, 2015) was being applied. The HYPROP system enables to measure the water retention curve and the hydraulic conductivity by the principle of the Extended Evaporation Method (EEM) in the range between saturation and close to the permanent wilting point, defined at pF 4.2. The end of the measurement cannot be correctly determined. It depends from the soil and the evaporation rate and generally varies between pF 3.7 for clay and sandy soils and 3.85 for silt and peat soils (Schindler et al., 2010). The dry bulk density is calculated from the cylinder volume and the mass of the oven dried $\left(105^{\circ} \mathrm{C}\right)$ sample at the end of the experiment

\section{Description of the method}

Undisturbed soil cores are sampled in stainless steel cylinders of $8 \mathrm{~cm}$ in diameter and $5 \mathrm{~cm}$ in height. The soil cores are slowly saturated by placing them in a pan of water. Two tensiometers are inserted vertically (Fig. 3) and the core is sealed at the bottom by clamping the cylinder with the assembly. The core is placed on a balance and the mass and pressure conditions in the soil core are controlled online. Water is added to the surface and already drained macropores are refilled up to the soil water pressure in the sample indicates full saturation. The soil surface is exposed to free evaporation and the measurement is started. Figure 3 shows the experimental setup of the HYPROP device.

Tensions and sample mass are recorded at selected time intervals between 10 minutes and several hours (Schindler et al., 2010). The hydraulic gradient is calculated on the basis of the tensions recorded during the time interval. The water flux is derived from the associated soil mass difference, respectively soil water volume difference. Single points of the water retention curve are calculated on the basis of the water loss per volume of the sample at time and are related to the mean tension in the sample at this time. The unsaturated hydraulic conductivity $(K)$ is calculated according to the DarcyBuckingham law (Equation 1). At the end of the measurement, the residual amount of storage water is derived from water loss by drying in the oven $\left(105^{\circ} \mathrm{C}\right)$ up to mass constancy.

$$
K\left(\Psi_{\text {mean }}\right)=\frac{\Delta m}{a A \rho_{H 2 O} \Delta t i_{m}}
$$

$\Psi_{\text {mean }}$ is the mean tension over the upper tensiometer at position $z_{1}(3.75 \mathrm{~cm}$ above the bottom of the sample) and the lower tensiometer at position $z_{2}\left(1.25 \mathrm{~cm}\right.$ above the bottom), geometrically averaged over a time interval of $\Delta t_{j}=t_{i+1}-t_{i}$, with $i$ $=1 . . . n, j=1 . . n-1 ; \Delta m$ is the sample mass difference in the time interval (assumed to be equal to the total evaporated water volume $\Delta V_{\mathrm{H} 2 \mathrm{O}}$ of the whole sample in the interval); $\rho_{\mathrm{H} 2 \mathrm{O}}$ is the density of water and is assumed to be $1 \mathrm{~g} \mathrm{~cm}^{-3}$; a is the flux factor (in the case of rigid soils $a=2$ ); $A$ is the cross sectional area of the sample and $i_{m}$ is the hydraulic gradient averaged over the time interval. 
Figure 3. Schematic illustration of the evaporation experiment and photo (in the middle position, UMS 2015) of the HYPROP system.

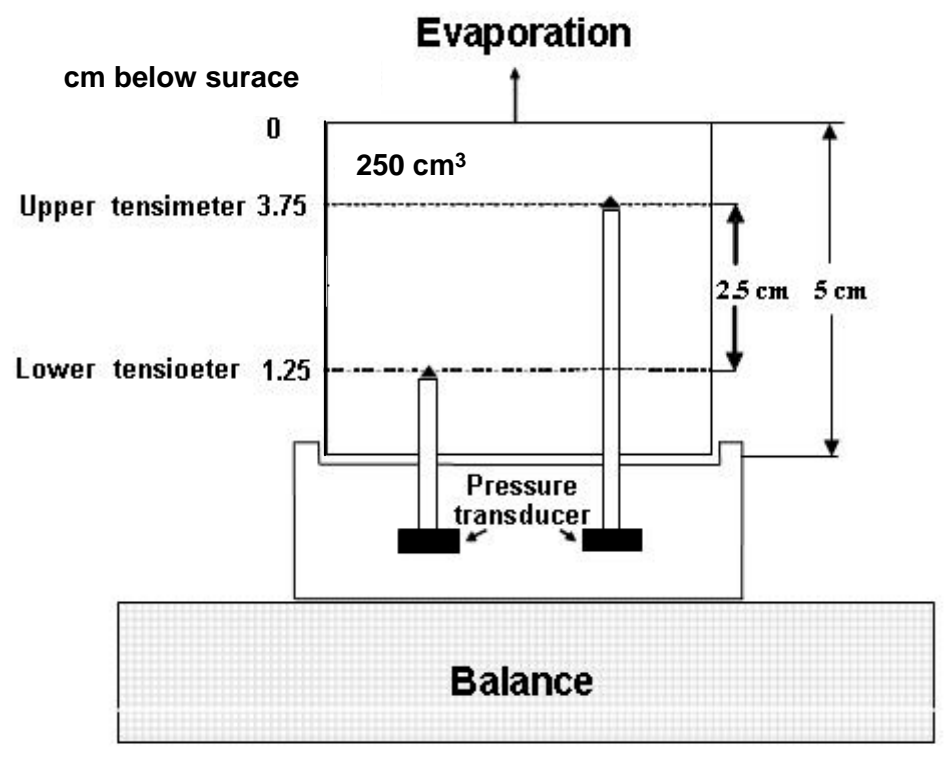

HYPROP system
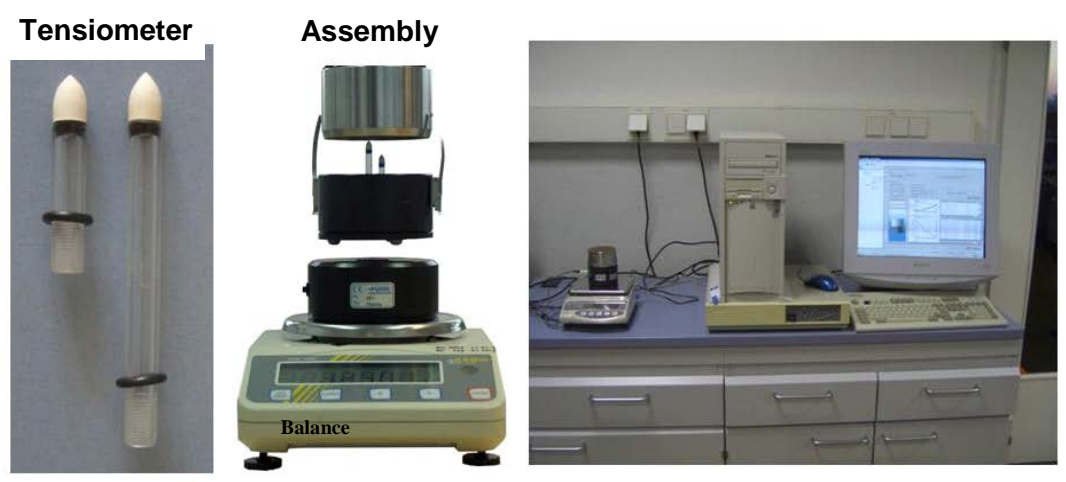

The initial water content is determined by the evaluation of the total water loss (evaporation part plus residual part) related to core volume. The dry bulk density is calculated by dividing the dry soil mass by the soil core volume. For this reason the volume of the tensiometer holes $\left(1 \mathrm{~cm}^{3}\right)$ is subtracted from the core. The total measurement time depends on both the evaporation rate and the soil water volume in the measurement range and varies between 3 days for clay soils and maximum 10 days for sand soils. Figure 4 presents an example of the two hydraulic functions measured with the EEM and the HYPROP device. 
Figure 4. Data points and fits of the water retention curve, left, and hydraulic conductivity function, middle and right, for a silty loam, Linfen China, screenshot (HYPROP fit software, UMS 2015)

\section{Retention $\theta(\mathbf{p F})$}

\section{Conductivity K(pF)}
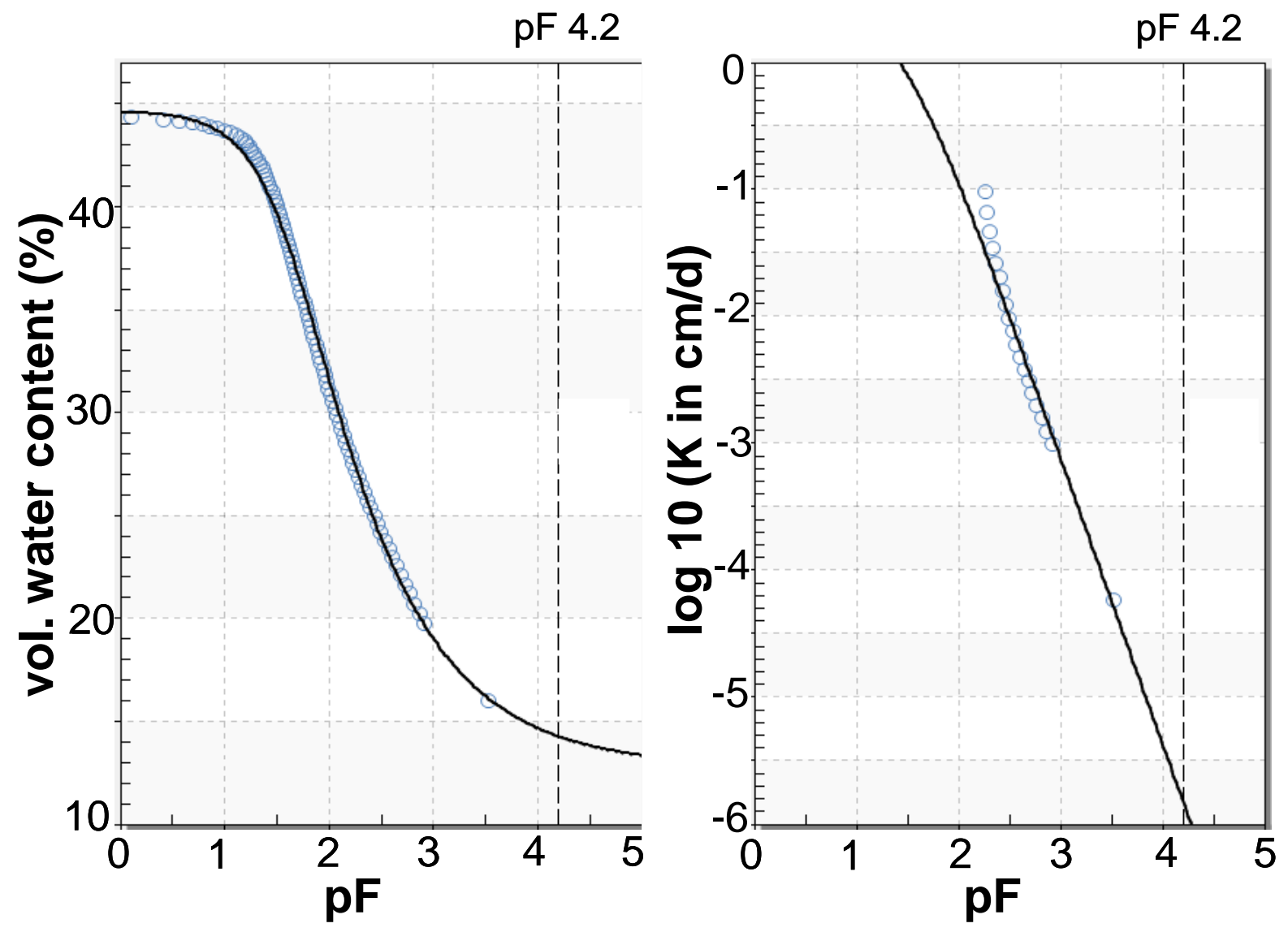

\subsection{OTHER METHODS USED TO CHARACTERISE THE SOIL SAMPLES}

2.4.1 PARTICLE SIZE ANALYSES: The particle size distribution was measured by gravitational sedimentation (DIN ISO 11277, 1994), and is based on the relationship between settling velocity and particle diameter. The pipette method is a direct sampling procedure. It consist in taking a small subsample by a pipette at a depth, $\mathrm{h}$ (10 $\mathrm{cm}$ for our analysis), at time, $\mathrm{t}$, at which all particles with a diameter larger than d have sedimented. Settling times are calculated using Stokes' Law (Eq. 3).

$d=\sqrt{\frac{18 \eta^{*} h}{g\left(\rho_{s}-\rho_{l}\right) * t}}$

where $\eta$ is the fluid viscosity, $h$ is the sedimentation depth, $d$ is the particle diameter, $\rho_{s}$ is the particle density, $\rho_{l}$ is the liquid density, $g$ is the gravitational acceleration, and $t$ is the time.

Preconditions are to use dispersed soil material and a solution free of organic carbon, destroyed by cooking in hydrogen peroxide $\left(\mathrm{H}_{2} \mathrm{O}_{2}\right)$. Dispersion is obtained by shaking the soil particles in sodium pyrophosphate $\left(\mathrm{Na}_{4} \mathrm{P}_{2} \mathrm{O}_{7}\right)$. The particle size classes are: clay $(<2 \mu \mathrm{m})$, fine silt $(2-6.3 \mu \mathrm{m})$, medium silt $(6.3-20 \mu \mathrm{m})$, fine silt $(20-63 \mu \mathrm{m})$. The sand fraction (fine sand $63-200 \mu \mathrm{m})$, medium sand $(200$ $630 \mu \mathrm{m})$, and coarse sand $(630-2000 \mu \mathrm{m})$ are determined by sieving the disperse solution.

\subsubsection{SOIL ORGANIC MATTER CONTENT AND ASH CONTENT}

The soil organic carbon content was determined after dry combustion according to the DIN ISO 10694 protocol (1994). The soil organic matter content was calculated according to equation (3).

soil organic matter content $=$ soil organic carbon content $* 1.724$ 


\section{RESULT AND CONCLUSIONS}

The presented soil physical properties are from different parts of the world. They are of different geological origin. The data set contains soil hydraulic functions of 173 soil samples of a wide range of texture classes, dry bulk densities and organic matter contents from 11 countries of America, Asia, Australia Africa and Europe.

The measurement of soil hydraulic properties like the water retention curve and the unsaturated hydraulic function is costly and time consuming with the classical methods. Furthermore, the results are affected by uncertainties. The EEM and HYPROP provide a system for simultaneously measuring both hydraulic functions in an easy way in three to ten days. The data provided here allow improving soil investigations and could be a help for research laboratory or private companies interested in soil and water management like irrigation, drainage and other. Furthermore, these data could be implemented in existing databases.

\section{DATA ACCESS}

The data are published under http://dx.doi.org/10.4228/ZALF.2003.273.

5 ACKNOWLEDGEMENTS: We would like to thank Dr. J. Pilz and Bernd Röber from the ZALF, Department of Landscape Information Systems for their great assistance.

\section{REFERENCES}

DIN ISO 10694: Bodenbeschaffenheit: Bestimmung des organischen Kohlenstoffgehaltes und des Gesamtkohlenstoffgehaltes nach trockener Verbrennung (Elementaranalyse), 1994.DIN ISO 11277, 1994: Bodenbeschaffenheit - Bestimmung der Partikelgröflenverteilung in Mineralböden - Verfahren durch Sieben und Sedimentation nach Entfernen der löslichen Salze der organischen Substanz und der Carbonate. Beuth-Verlag. Berlin. 44 pp.

FAO: Guidelines for soil description. 3rd Edition, Rome, 1990.

Nemes, A., M.G. Schaap, F.J. Leij, and J.H.W. Wösten: Description of the unsaturated soil hydraulic database UNSODA, version 2.0. J. Hydrol. 251:151-162, 2001.

Schindler, U.: Ein Schnellverfahren zur Messung der Wasserleitfähigkeit im teilgesättigten Boden an Stechzylinderproben. Arch. Acker- u. Pflanzenbau u. Bodenkd., Berlin 24: 1-7, 1980.

Schindler U, Durner W, von Unold G, Müller L and Wieland R.: The evaporation method - Extending the measurement range of soil hydraulic properties using the air-entry pressure of the ceramic cup. J. Plant Nutr. Soil Sci. 173(4): 563-572, 2010.

UMS: UMS GmbH Munich, HYPROP৫ - Laboratory evaporation method for the determination of pFcurves and unsaturated conductivity. Online: http://www.ums-muc.de/en/products/soil laboratory.html, accessed on Jan 10, 2015, 2015.

Wösten, J.H.M., A. Lilly, A. Nemes and C. Le Bas.: Development and use of a database of hydraulic properties of European soils. Geoderma 90:169-185, 1999.

WRB: World Reference Base for Soil Resources, A Framework for International Classification, Correlation and Communication, FAO Rome, 2006, World Soil Resources Reports 103, 145p., 2006.

Toth, G. (ed): European HYdrological Data Inventory (EU-HYDI), JRC Technical Reports. p. 165. ISBN: 978-92-79-32355 (pdf), 2013. 